\title{
Circular RNA: new star, new hope in cancer
}

\author{
Zikang Zhang ${ }^{1 \dagger}$, Qing Xie ${ }^{1 \dagger}$, Dongmei He${ }^{2}$, Yuan Ling ${ }^{1}$, Yuchao Li ${ }^{1}$, Jiangbin $\mathrm{Li}^{i^{*}}$ and Hua Zhang ${ }^{1^{*}}$ (D)
}

\begin{abstract}
Background: Circular RNAs are a new class of endogenous non-coding RNA that can function as crucial regulators of diverse cellular processes. The diverse types of circular RNAs with varying cytogenetics in cancer have also been reported.

Main body of the abstract: Circular RNAs can act as a microRNA sponge or through other mechanisms to regulate gene expression as either tumor inhibitors or accelerators, suggesting that circular RNAs can serve as newly developed biomarkers with clinic implications. Here, we summerized recent advances on circular RNAs in cancer and described a circular RNA network associated with tumorigenesis. The clinical implications of circular RNAs in cancer were also discussed in this paper.

Short conclusion: Growing evidence has revealed the crucial regulatory roles of circular RNAs in cancer and the elucidation of functional mechanisms involving circular RNAs would be helpful to construct a circRNA-miRNAmRNA regulatory network. Moreover, circular RNAs can be easily detected due to their relative stability, widespread expression, and abundance in exosomes, blood and saliva; thus, circular RNAs have potential as new and ideal clinical biomarkers in cancer.
\end{abstract}

Keywords: Circular RNA, MicroRNA sponge, Cancer, Regulation network, Exosome, Clinical implication

\section{Background}

More than $75 \%$ of non-coding RNAs have been found in transcription of the human genome [1]. Circular RNAs (circRNAs), $100 \mathrm{bp}$ to $4 \mathrm{~kb}$ in size, were regarded as non-functional by-products of aberrant RNA splicing $[2,3]$. Recently, with the improvements in novel next-generation deep sequencing and bioinformatics technology, an increasing number of circRNAs with regulatory functions were found in many tapes of cancers [4-6]. Unlike linear transcripts, the structures of circRNAs are covalently closed loops without tails in the $5^{\prime}-3^{\prime}$ port, which stabilizes the structures enough to resist digestion by RNase [7-10]. CircRNAs are generally classified as three types: exonic circRNAs, exonic-intronic circRNAs and intronic circRNAs. Most exonic circRNAs exist in cytoplasm, whereas the other two are mainly found in cell nucleus [10]. Some circRNAs exist in human body fluid, making them easy to be detected $[9,10]$. Most circRNAs are extremely

\footnotetext{
*Correspondence: 86971828@qq.com; huazhang@gdmu.edu.cn

${ }^{\dagger}$ Zikang Zhang and Qing Xie contributed equally to this work.

'Guangdong Provincial Key Laboratory of Medical Molecular Diagnostics,

Institute of Laboratory Medicine, Guangdong Medical University, Dongguan

523808, China

Full list of author information is available at the end of the article
}

abundant, relatively stable and widely expressed in eukaryotic cells, suggesting that circRNAs have potential regulatory roles [11].

Some circRNAs discovered in human tissues have been related to diverse cellular processes, including senescence, growth and apoptosis, etc. [12, 13]. Moreover, deregulated circRNA expression profiles correlated with some cancers have been identified, suggesting that circRNAs can function as tumor inhibitors or accelerators [14]. Emerging evidence that circRNAs are important regulators in cancer implies they might serve as new clinical biomarkers in cancer $[15,16]$. This review concentrates on recent advances in circRNA research in cancer and summarizes the current significance of circRNAs in the clinical implications of cancer.

\section{The regulation mechanisms of circRNAs}

The regulation mechanisms of circRNAs have been revealed by increasing studies. The most notable of these mechanisms is that circRNAs can work as microRNA (miRNA) sponges. CircRNAs can block the binding of miRNAs with the 3' UTR of a specific gene by directly binding to miRNAs, thus indirectly regulating the gene expression $[17,18]$. For example, ciRS-7 can function as

(c) The Author(s). 2018 Open Access This article is distributed under the terms of the Creative Commons Attribution 4.0 International License (http://creativecommons.org/licenses/by/4.0/), which permits unrestricted use, distribution, and reproduction in any medium, provided you give appropriate credit to the original author(s) and the source, provide a link to the Creative Commons license, and indicate if changes were made. The Creative Commons Public Domain Dedication waiver (http://creativecommons.org/publicdomain/zero/1.0/) applies to the data made available in this article, unless otherwise stated. 
a sponge of miR-7 and consequently repress its function in cancer [19]. The second mechanism is that circRNAs play as regulators in gene expression by competing with mRNA production in pre-mRNA splicing [20]. Another mechanism of circRNAs involves binding to RNA binding proteins (RBPs) as transcription regulators $[15,16]$. Moreover, circRNAs can serve as mRNA traps, another form of alternative splicing, and remove start codons from mature mRNAs to reduce protein translation in cancer [21] (Fig. 1).

\section{Translation of circRNAs}

Translation of ncRNAs is poorly noted due to the classic ORFs longer than 100 codon are lacking. With more research on small open reading frames (sORFs), the proteins or peptides with biological functions that are translated by ncRNAs have received more attention [22]. CircRNAs, as a novel form of ncRNAs described in recent studies, have been found to be abundantly expressed in the cytoplasm, suggesting that they have the potential to regulate disease processes via translation of proteins or peptides [23]. Four mechanisms of circRNA protein or peptide translation have been identified. Wang et al. found that artificial synthetic circRNAs with internal ribosome entry sites (IRESs) can be translated [24]. Another mechanism has been found that circRNAs were effectively translated according to roll circle amplification (RCA) in human liver cells [25]. In addition, Yun et al. found that translation of circRNAs was driven by $\mathrm{N}^{6}$-methyladenosine $\left(\mathrm{m}^{6} \mathrm{~A}\right)$ in human cells [26]. Recent research has found a novel cap-independent translation mechanism in circRNAs [22]. There have also been exciting breakthroughs in the study of circRNA protein translation as it relates to the regulation of cancer progression. FBXW7-185aa, which is translated from circ-FBXW7, regulates the stability of c-myc and inhibits the development of malignant glioma. This suggests that the functional protein resulting from circRNA translation may be a biomarker or therapeutic target for cancer. This

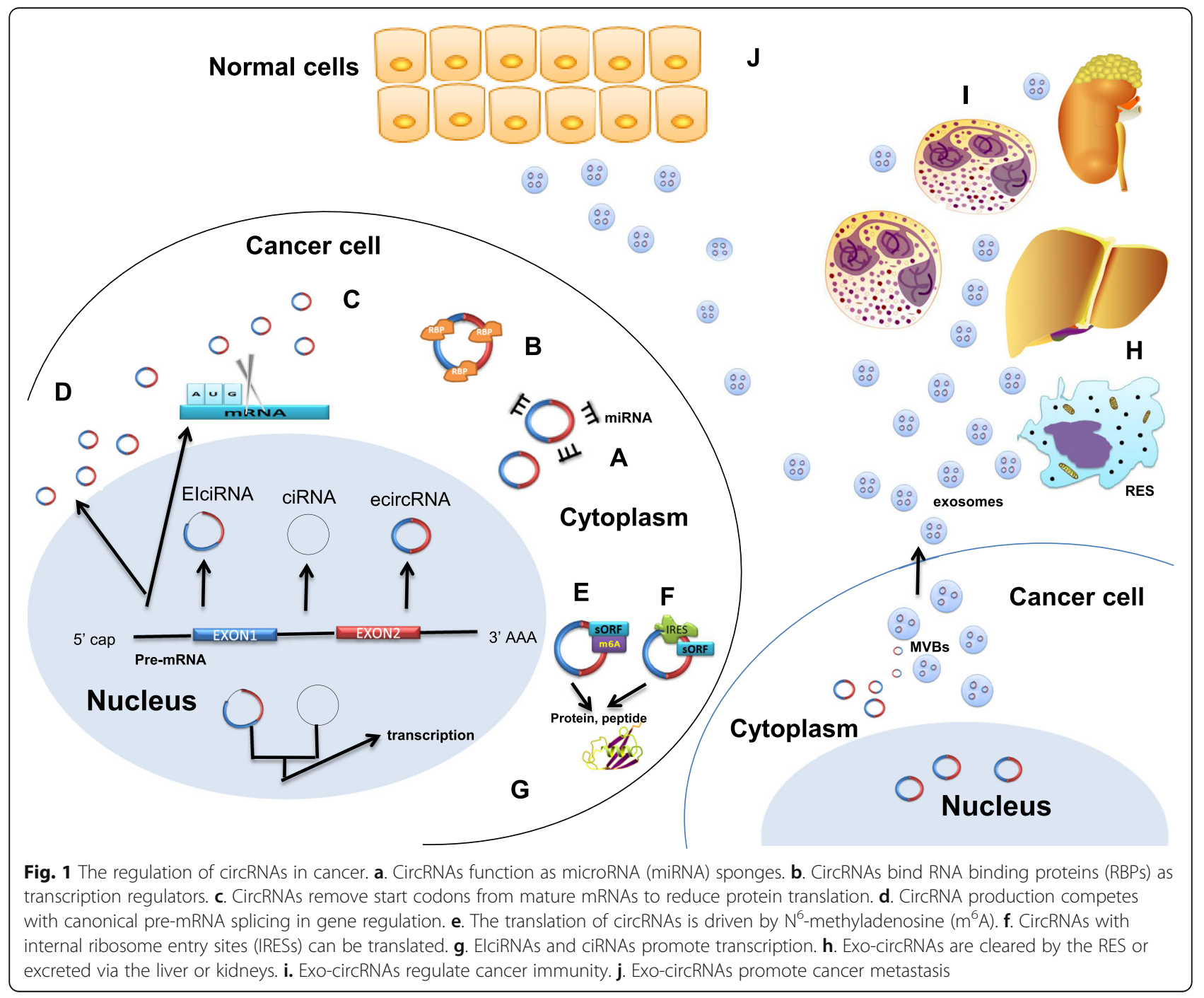


demonstrates a new regulation mechanism of circRNAs in cancer [27] (Fig. 1).

\section{Exosome delivery of circRNAs in cancer}

Extracellular vesicles released by cells can be divided into three categories according to origin and size, including microvesicles, apoptotic bodies, and exosomes [28]. Many biological molecules exist in EVs, such as DNA, RNA, bioactive lipids, and proteins [28, 29]. Exosomes are approximately 30 to $100 \mathrm{~nm}$ in diameter and can be derived from many cells; in addition, exosomes can be transported from the originating cell to the recipient cell [30]. Exosomes with coding transcripts and non-coding RNAs are easily discovered in accessible body fluids, particularly blood, and are released more frequently by tumor cells, implying that exosomes can act as cancer communication agents to help cancer cells escape from immune surveillance and contribute to tumor formation [30, 31].

Recently, a number of studies have found that more exosomes are released from cancer cells than from normal cells. It was reported that circRNAs in gastric cancer (GC) can be transferred from GC cells to normal cells via exosomes, indicating that exo-circRNAs are important in the peritoneal metastasis of GC [32]. Moreover, deregulated circRNAs have been found in the exosomes of different cancers, and cancer-associated chromosomal translocations generate fusion-circRNAs-exosomes that can promote cellular transformation and tumor progression [33, 34]. Interestingly, other studies have also found that exosomes can participate in the clearance of intracellular circRNAs, and exosomes themselves can be further cleared by the reticuloendothelial system (RES) or excreted via the liver or kidneys [35, 36] (Fig. 1).

\section{Expression profiles and identification of circRNAs in cancer}

As microarray chip and next-generation sequencing technologies have been developed, many circRNAs were examined or identified in cancer samples. The expression profiles of circRNAs during the early stages of pancreatic ductal adenocarcinoma (PDAC) have been demonstrated, which revealed that deregulated circRNAs may participate in the progression of PDAC and potentially serve as a novel therapeutic biomarker [37, 38]. In another study, microarray analysis also showed that circRNA_100855 and circRNA_104912 are the most significantly deregulated circRNAs in laryngeal cancer tissues, whereas circRNA_001059 and circRNA_000167 are significantly deregulated in radioresistant esophageal cancer $[39,40]$. In colorectal cancer, 379 dysregulated circRNAs were identified using circRNA microarray analysis [41].
In gliomas, RNA-Seq data showed the existence of over 476 deregulated circRNAs [42]. A recent study identified circRNAs associated with breast cancer subtypes using Circ-Seq [43]. Additionally, circRNA expression profiles in KRAS mutant colon cancer were identified from RNA-Seq data [44].

Interestingly, by combining microarray circRNA expression profiles with bioinformatics target prediction and sequence analysis, many deregulated circRNAs with miRNA response elements (MREs) have been identified in basal cell carcinoma (BBC) and cutaneous squamous cell carcinoma (CSCC) [45, 46]. More recently, it was reported that 69 differentially expressed circRNAs might interact with certain miRNAs to influence mRNA expression in gastric cancer (GC) [47].

\section{The circRNA regulation network in cancer}

Although the overall mechanisms of circRNAs in cancers have not been entirely elucidated, crucial regulatory roles of circRNAs in cancer have been revealed. Recent studies on circRNAs mainly focused on the roles as miRNA sponges, interactions with binding proteins and translation into proteins or peptides [22, 48]. An increasing amount of evidence has shown the involvement of circRNAs in regulatory signaling pathways that influence the progression and development of cancer,making circRNAs a potential therapeutic target [49]. Here, a clearer circRNA regulation network in cancer and its relevance to tumorigenesis is summarized (Fig. 2).

CircRNAs regulate apoptosis in cancer. It has been shown that circ-Foxo3 can promote MDM2-induced degradation of $\mathrm{p} 53$ by binding to MDM2 and p53; however, circ-Foxo3 contributes more to repression of MDM2-induced Foxo3 ubiquitination by binding to Foxo3 and thus increasing the expression of the downstream gene PUMA to induce apoptosis in breast carcinoma [50, 51]. In another study, increased circUBAP2 was found to upregulate its target $\mathrm{Bcl}-2$ and inhibit apoptosis in osteosarcoma by sponging miR-143 [52].

CircRNAs regulate the cell cycle in cancer. It has been demonstrated that miR-7 can inhibit cancer progression by suppressing CCNE1 and PIK3CD in hepatocellular carcinoma (HCC) $[53,54]$. A recent study proved that ciRS-7 can function as an oncogene to halt the cell cycle by upregulating CCNE1 and promoting cell proliferation via PI3K/AKT pathway by directly targeting miR-7 in HCC [55]. Moreover, deregulated miR-217 can target $\mathrm{EZH} 2$, which can increase the level of cyclin D1 to accelerate cell cycle progression and lead to malignant transformation. In addition, upregulated circ100284 can bind miR-217 and promote cell cycle progression in arsenic-induced skin cancer [56].

CircRNAs regulate cancer proliferation. The overall expression of circ-CDR1 can also increase EGFR expression 


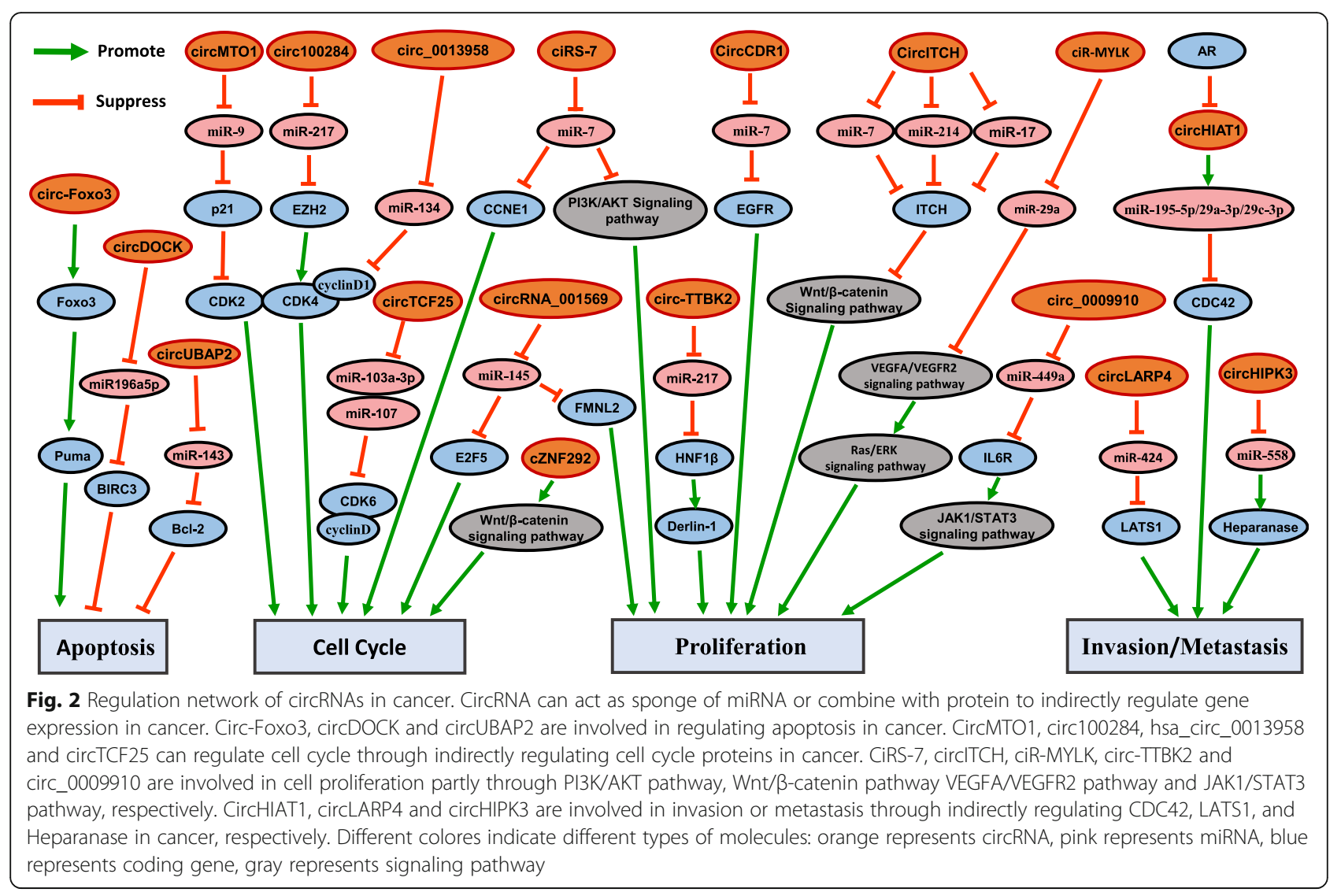

and lead to cell proliferation by sponging miR-7 in HCC [57]. Additionally, it was revealed that circ-ITCH can inhibit miR-7 to partly enhance the effect of ITCH, which suppresses cell proliferation by inhibiting the $\mathrm{Wnt} / \mathrm{\beta}-\mathrm{Ca}-$ tenin pathway in lung cancer and ESCC $[58,59]$. In bladder cancer, another study demonstrated that circTCF25 can suppress miR-107 and miR-103a-3p to accelerate proliferation and migration, which led to increased CDK6 and further activation of cyclin D to promote cell cycle progression into the $S$ phase [60].

CircRNAs regulate invasion and metastasis in cancer. Upregulated androgen receptor (AR) expression can accelerate the development of clear cell renal cell carcinoma (CCRCC) by inhibiting miR-145 [61]. Recently, a new mechanism of AR regulation was revealed. AR can enhance migration and invasion through circHIAT1-microRNA-protein signaling, and circHIAT1 can increase signaling by serving as a miRNA suppressor more so than a miRNA sponge in CCRCC [62]. Previous studies demonstrated that E2F5 can promote cell growth and is frequently observed in diverse human cancers [63]. Furthermore, overexpression of circ_001569 accelerates proliferation and invasion through targeting miR-145, which suppresses E2F5 and FMNL2 in colorectal cancer (CRC) [64]. In addition, it was reported that circHIPK3 competes with miR-558 to inhibit heparinase and cause rapid invasion metastasis in bladder cancer [65].

Although the rough roles of several circRNAs in some cancers have been confirmed, the functions and regulation pathways of most circRNAs in cancer remain to be revealed.

\section{Clinically relevant implications of circRNAs in cancer}

Differential expression profiling analysis and functional studies of circRNAs in tumors are important for the further understanding of circRNAs and cancer. Meanwhile, similar to microRNAs and lncRNAs, circRNAs also show potential as new independent diagnostic and prognostic biomarkers, which provides new approaches to improve clinical diagnosis and treatment. Here, we summarize currently known cancer-associated circRNAs related to clinical implications in Table 1 and mainly discuss the potential of some circRNAs as clinical biomarkers.

\section{CircRNAs in colorectal cancer}

Colorectal cancer has become the fourth most deadly cancer in the world, and its occurrence is related to changes in individual genetics [66]. CircRNAs might potentially be a new biomarker to facilitate CRC diagnosis and prognosis. A positive correlation between several deregulated circRNAs in CRC and clinical indicators has 
Table 1 Cancer associated circRNAs

\begin{tabular}{|c|c|c|c|c|c|c|}
\hline Cancer type & CircRNA & Samples & Cases & Expression & Association & Reference \\
\hline \multirow[t]{2}{*}{ Bladder cancer } & CircPTK2 & Tissue/blood & 40 pairs & Up & $\begin{array}{l}\text { Poor differentiation, } \\
\text { higher lymph node } \\
\text { metastasis and T stage }\end{array}$ & [83] \\
\hline & Circ-ITCH & Tissue & 72 pairs & Down & $\begin{array}{l}\text { Higher TNM stage and } \\
\text { histological grade }\end{array}$ & [96] \\
\hline \multirow[t]{2}{*}{ Esophageal cancer } & Has_circ_0067934 & Tissue & 51 pairs & Up & $\begin{array}{l}\text { Poor differentiation and } \\
\text { higher TNM stage }\end{array}$ & [84] \\
\hline & CiRS-7 & Tissue & 86 pairs & Up & $\begin{array}{l}\text { Higher clinical stage and } \\
\text { pathological grade }\end{array}$ & [97] \\
\hline \multirow[t]{10}{*}{ Colorectal cancer } & Hsa_circ_0007534 & Tissue & 33 pairs & Up & $\begin{array}{l}\text { Higher clinical stage and } \\
\text { lymph node metastasis }\end{array}$ & [68] \\
\hline & Hsa_circ_001988 & Tissue & 31 pairs & Down & $\begin{array}{l}\text { Associated with } \\
\text { differentiation and } \\
\text { perineural invasion }\end{array}$ & [67] \\
\hline & Hsa_circ_0000069 & Tissue & 30 pairs & Up & $\begin{array}{l}\text { Associated with patient } \\
\text { age and TNM stage }\end{array}$ & [98] \\
\hline & CiRS-7 & Tissue & 40 pairs & Up & $\begin{array}{l}\text { Higher T-stage and } \\
\text { metastasis/poor prognosis }\end{array}$ & [70] \\
\hline & Circular BANP & Tissue & 35 pairs & Up & Unknown & [41] \\
\hline & CircRNA0003906 & Tissue & 122 pairs & Down & $\begin{array}{l}\text { Poor differentiation, } \\
\text { higher lymphatic } \\
\text { metastasis/diagnosis } \\
\text { value }\end{array}$ & [99] \\
\hline & Hsa_circ_0001649 & Tissue/blood & Total 146 & Down (tissue)/up (blood) & $\begin{array}{l}\text { Associated with } \\
\text { differentiation }\end{array}$ & [100] \\
\hline & Circ_0014717 & Tissue & 46 pairs & Down & $\begin{array}{l}\text { Associated with TNM stage } \\
\text { and distal metastasis/poor } \\
\text { prognosis }\end{array}$ & [69] \\
\hline & Hsa_circ_0000567 & Tissue & 102 pairs & Down & $\begin{array}{l}\text { Lower clinical stage and } \\
\text { lymph node metastasis/ } \\
\text { diagnosis value }\end{array}$ & [101] \\
\hline & CircHIPK3 & Tissue & Total 218 & Up & $\begin{array}{l}\text { Associated with TNM } \\
\text { stage and metastasis/poor } \\
\text { prognosis }\end{array}$ & [102] \\
\hline \multirow[t]{8}{*}{ Hepatocellular carcinoma } & CiRS-7 & Tissue & 108 pairs & Up (39.8\%)/down (60.2\%) & Associated with MVI & [103] \\
\hline & Hsa_circ_0005075 & Tissue & 66 pairs & Up & $\begin{array}{l}\text { Larger size tumors/ } \\
\text { diagnostic potential }\end{array}$ & {$[75]$} \\
\hline & Hsa_circ_0001649 & Tissue & 89 pairs & Down & $\begin{array}{l}\text { Larger tumor size and } \\
\text { tumor embolus formation/ } \\
\text { poor prognosis }\end{array}$ & [104] \\
\hline & Hsa_circ_0003570 & Tissue & 107 pairs & Down & $\begin{array}{l}\text { Associated with tumor } \\
\text { diameter, differentiation } \\
\text { and vascular formation }\end{array}$ & [73] \\
\hline & CircMTO1 & Tissue & 261 pairs & Down & Poor prognosis & [74] \\
\hline & CircZKSCAN1 & Tissue & 102 pairs & Down & Potential diagnostic value & [76] \\
\hline & Hsa_circ_0000673 & Tissue & 51 pairs & Up & Poor overall survival & [105] \\
\hline & CircC3P1 & Tissue & 47 pairs & Down & $\begin{array}{l}\text { Higher TNM stage, tumor } \\
\text { size and vascular invasion }\end{array}$ & [106] \\
\hline \multirow[t]{2}{*}{ Gastric cancer } & Hsa_circ_002059 & Tissue/plasma & Total 147 & Down & $\begin{array}{l}\text { Associated with distal } \\
\text { metastasis, TNM stage, } \\
\text { gender and age }\end{array}$ & [11] \\
\hline & Hsa_circ_0000190 & Tissue/plasma & 104 pairs & Down & $\begin{array}{l}\text { Associated with tumor } \\
\text { diameter, metastasis } \\
\text { and TNM stage (tissue)/ } \\
\text { CEA (plasma) }\end{array}$ & [81] \\
\hline
\end{tabular}


Table 1 Cancer associated circRNAs (Continued)

\begin{tabular}{|c|c|c|c|c|c|c|}
\hline Cancer type & CircRNA & Samples & Cases & Expression & Association & Reference \\
\hline & Circ-104916 & Tissue & 70 pairs & Down & $\begin{array}{l}\text { Higher tumor stage and } \\
\text { lymphatic metastasis }\end{array}$ & {$[80]$} \\
\hline & CircRNA_100269 & Tissue & 112 pairs & Down & $\begin{array}{l}\text { Associated with histological } \\
\text { subtypes and nodes invasion }\end{array}$ & [107] \\
\hline & Hsa_circ_0000745 & Tissue/plasma & 20 pairs & Down & $\begin{array}{l}\text { Associated with tumor } \\
\text { differentiation (tissue)/ } \\
\text { node metastasis (plasma) }\end{array}$ & [108] \\
\hline & Hsa circ 0074362 & Tissue & 127 pairs & Down & $\begin{array}{l}\text { Associated with CA19-9 } \\
\text { and lymphatic metastasis }\end{array}$ & [109] \\
\hline & CircPVT1 & Tissue & 187 pairs & Up & $\begin{array}{l}\text { Associated with overall } \\
\text { survival }\end{array}$ & [110] \\
\hline & Hsa_circ_0006633 & Tissue/plasma & Total 338 & Down(tissue)/up(plasma) & $\begin{array}{l}\text { Associated with distal } \\
\text { metastasis and CEA } \\
\text { (tissue) }\end{array}$ & [78] \\
\hline & Hsa_circ_0001895 & Tissue & Total 257 & Down & $\begin{array}{l}\text { Associated with } \\
\text { differentiation, Borrmann } \\
\text { type and CEA }\end{array}$ & [111] \\
\hline & Hsa_circ_0014717 & Tissue/gastric juice & Total 122 & Down & $\begin{array}{l}\text { Associated with tumor } \\
\text { stage, metastasis, CEA } \\
\text { and CA19-9 (tissue) }\end{array}$ & [79] \\
\hline & Hsa_circ_0003159 & Tissue & 108 pairs & Down & $\begin{array}{l}\text { Higher gender, distal } \\
\text { metastasis and node } \\
\text { metastasis }\end{array}$ & [112] \\
\hline & Hsa_circ_0000181 & Tissue/plasma & Total 115 & Down & $\begin{array}{l}\text { Associated with tumor } \\
\text { diameter, metastasis } \\
\text { and CA19-9 (tissue)/ } \\
\text { differentiation and CEA }\end{array}$ & {$[82]$} \\
\hline & Hsa_circ_0000520 & Tissue & 56 pairs & Down & Higher TNM stage & [113] \\
\hline & CircMYO9B & Tissue & 21 pairs & Up & Lower survival rate & [114] \\
\hline \multirow[t]{3}{*}{ Breast cancer } & CircGFRA1 & Tissue & Total 222 & Up & $\begin{array}{l}\text { Higher tumor size, TNM } \\
\text { stage, } \\
\text { lymphatic metastasis } \\
\text { and histological grade }\end{array}$ & [115] \\
\hline & Cir-ITCH & Tissue & Total 78 & Up & Associated with age & [58] \\
\hline & CircRNA_100876 & Tissue & 101 pairs & Up & $\begin{array}{l}\text { Associated with lymphatic } \\
\text { metastasis and advanced } \\
\text { stage }\end{array}$ & [116] \\
\hline Osteosarcoma & CircPVT1 & $\begin{array}{l}\text { Tissue/serum/lung } \\
\text { metastasis }\end{array}$ & Total 80 & Up & $\begin{array}{l}\text { Poor prognosis/diagnosis } \\
\text { value }\end{array}$ & [95] \\
\hline \multirow[t]{2}{*}{ Lung cancer } & CircFADS2 & Tissue & 43 pairs & Up & $\begin{array}{l}\text { Poor differentiation, } \\
\text { advanced TNM stage and } \\
\text { lymphatic metastasis }\end{array}$ & [117] \\
\hline & CircRNA_102231 & Tissue & 57 pairs & Up & $\begin{array}{l}\text { Associated with TNM stage } \\
\text { and lymph node metastasis }\end{array}$ & [118] \\
\hline
\end{tabular}

been identified. For example, qRT-PCR analysis of 31 CRC patients showed that circ_001988 expression is downregulated and significantly associated with peripheral invasion and less differentiation [67]. Additionally, higher expression of hsa_circ_0007534 in CRC tumor tissue is associated with neoplasm staging and lymphatic metastasis [68]. CircRNAs may be used to predict prognosis in CRC, as Wang et al. found that patients with downregulated hsa_circ_0014717 have poorer OS and poor prognosis [69]. Moreover, overexpressed ciRS-7 can promote aggressiveness of CRC and is positively related with a high $\mathrm{T}$-stage and lymphatic and distant metastasis, implying that ciRS-7 might be releated to a worse prognosis [70].

\section{CircRNAs in hepatocellular carcinoma}

HCC is responsible for nearly $90 \%$ of primary malignancies of the liver, and patients with advanced stage disease always have poor prognoses [71, 72]. CircRNAs might function as a prognostic predictor and therapeutic target 
in HCC. One study demonstrated that downregulated circ_0003570 is closely related to tumor diameter, differentiation status and vascular formation in HCC [73]. Another study revealed that downregulated circMTO1 is associated with dismal prognosis in $\mathrm{HCC}$ and that upregulated circMTO1 can act as a sponge of miR-9 to increase the level of p21 and inhibit the malignant development of HCC [74]. Moreover, upregulated circ_0005075 is correlated with larger tumor size and increased cell adhesion, whereas downregulated circZKSCAN1 is involved in several cancer-related signaling pathways to suppress the growth of HCC. Both of the AUROCs for these circRNAs indicated a potential diagnostic value $[75,76]$.

\section{CircRNAs in gastric cancer}

Although many efforts have been made to improve the diagnosis and therapy of GC, five-year OS rates in gastric cancer patients are still less than 30\% [77]. New biomarkers for diagnosis and therapy are still necessary, and up to now, mostly low expression of circRNAs in GC has been observed. The clinical samples have been derived from not only tumor tissue and plasma but also gastric juice, suggesting that circRNAs may be useful potential biomarkers [78, 79]. The downregulated circ-104916 has been found to be associated with higher invasion, neoplasm staging and lymph node metastasis in GC [80]. Additionally, both circ_0000190 and circ_002059 are more lowly expressed in $\mathrm{GC}$ tissues, which is relevant to some clinical parameters $[11,81]$. Furthermore, the expression of circ_0000181 is significantly decreased in GC, and circ_0000181 is associated with many clinical indicators in GC patients, implying that it might serve as a good biomarker [82].

\section{CircRNAs in other cancers}

In breast cancer, downregulated circ-Foxo3 can enhance cell survival and decrease cell apoptosis [52]. In bladder cancer, circPTK2 is highly expressed among fourty pairs of tissues and blood specimens, and its expression level is significantly associated with lower differentiation, N2-N3 lymphatic metastasis, and higher T stage [83]. In ESCC, circ_0067934 is significantly upregulated and associated with poor differentiation, whereas cir-ITCH is downregulated and functions as a tumor inhibitor by regulating tumor cell viability $[59,84]$. In lung cancer and colorectal cancer, downregulated circ-ITCH plays an important tumor suppressor role [58, 85]. Upregulated circSMARCA5 can accelerate cell cycle and suppress apoptosis in prostate cancer [86]. In glioma, both circ-TTBK2 and cZNF292 are highly expressed and play crucial oncogenic roles in promoting glioma malignancy progression $[87,88]$.

\section{CircRNAs in chemoradiation resistance}

The emergence of chemoradiation resistance can lead to poor prognosis or recurrence [89-91]. At present, studies have found changed circRNA expression profiles in radioresistant ESCC cells, ADM-resistant breast cancer cells and 5-FU-based chemoradiation-resistant CRC cells. Through biological analysis, some circRNAs have been found to influence the chemoradiation resistance of cancer cells by regulating specific genes or pathways [40, 92-94]. Another study has revealed that downregulated circPVT1, which is overexpressed in osteosarcoma tissues and chemoradiation-resistant cells, can weaken expression of the classical chemoradiation resistance gene $\mathrm{ABCB} 1$ to reduce the resistance to cisplatin and doxorubicin in osteosarcoma cells [95]. Although there is still very little research regarding circRNAs and chemoradiation resistance in cancer, it has a great potential that circRNAs can be used as novel biomarkers to predict the efficiency of chemoradiation and prognosis or recurrence in drug-resistant cancers.

\section{Conclusions}

Many studies indicated that circRNAs, similar to miRNAs and lncRNAs, may have significant regulatory effects on pathophysiologic processes, including tumorigenesis. The connections of circRNAs with cancer has become a hot research field. CircRNAs can be easily detected due to their relative stability, widespread expression, and abundant presence in exosomes, blood and saliva, indicating that circRNAs might be novel and ideal diagnostic and prognostic biomarkers in cancer. In this paper, we drew conclusions about recent advances on circRNAs in cancer and presented a circRNA-mediated network involved in cell cycle control, apoptosis, proliferation, invasion and metastasis in cancer.

At present, some circRNA expression profiles in several cancers have been identified; however, there are still many questions that need to be addressed. Further investigation is needed regarding the various gene regulatory mechanisms of circRNAs other than miRNA sponges. The important relationship between the exo-circRNAs and tumor metastasis and the development of novel and valid ways to predict target genes of circRNAs using bioinformatics, among other issues, need to be addressed. This will provide new insights into circRNAs to construct circRNA-miRNA-mRNA regulation networks, reveal cancer pathogenesis mechanisms and seek novel potential diagnosis biomarker or therapeutic targets for future cancer management.

\footnotetext{
Abbreviations

Akt/PKB: v-akt murine thymoma viral oncogene homolog 1/protein kinase B; AR: Androgen receptor; BBC: Basal cell carcinoma; BC: Breast cancer; CCNE1: Cyclin E1; CCRCC: Clear cell renal cell carcinoma; CDK2: Cyclindependent kinase2; CDK4: Cyclin-dependent kinase4; CDK6: Cyclindependent kinase6; circRNAs: Circular RNAs; CRC: Colorectal cancer; ESCC: Esophageal cancer; EVs: Extracellular vesicles; GC: Gastric cancer;
} 
HCC: Hepatocellular carcinoma; miRNA: microRNA; mTOR: Mammalian target of rapamycin; MVI: Microvascular invasion; ncRNA: Non-coding RNA; OS: Overall survival; PDAC: Pancreatic ductal adenocarcinoma; PIK3CD: Phosphoinositide 3-kinase catalytic subunit delta; RBP: RNA binding proteins; RES: Reticuloendothelial system; RT-PCR: Reverse transcription PCR

\section{Funding}

This work was supported by the National Natural Science Foundation of China (81300398), the Natural Science Foundation of Guangdong Province (2015A030313528), the 2013 Sail Plan "Introduction of the Shortage of Top-Notch Talent" Project (YueRenCaiBan [2014] 1) and the Project of Administration of Traditional Chinese Medicine of Guangdong Province $(20141277,20162079)$. The funding body had no role in the design of the study and collection, analysis, and interpretation of data and in writing the manuscript

\section{Authors' contributions}

ZKZ and QX wrote the manuscript and created the figures: $\mathrm{DMH}, \mathrm{YCL}$ and $\mathrm{YL}$ collected the related paper; $\mathrm{BJ}$ and $\mathrm{HZ}$ provided guidance and revised this manuscript. All authors approved the final manuscript.

\section{Ethics approval and consent to participate}

Not applicable.

\section{Consent for publication}

Not applicable.

\section{Competing interests}

The authors declare that they have no competing interests.

\section{Publisher's Note}

Springer Nature remains neutral with regard to jurisdictional claims in published maps and institutional affiliations.

\section{Author details}

'Guangdong Provincial Key Laboratory of Medical Molecular Diagnostics, Institute of Laboratory Medicine, Guangdong Medical University, Dongguan 523808, China. ${ }^{2}$ Department of Gynaecology and Obstetrics, Huizhou Hospital of Traditional Chinese Medicine, Huizhou 516000, China.

Received: 2 January 2018 Accepted: 23 July 2018

Published online: 20 August 2018

\section{References}

1. Wallaert A, Durinck K, Taghon T, Van Vlierberghe P, Speleman F. T-ALL and thymocytes: a message of noncoding RNAs. J Hematol Oncol. 2017;10(1):66.

2. Qu S, Yang X, Li X, Wang J, Gao Y, Shang R, et al. Circular RNA: a new star of noncoding RNAs. Cancer Lett. 2015;365:141-8.

3. Cocquerelle C, Mascrez B, Hetuin D, Bailleul B. Mis-splicing yields circular RNA molecules. FASEB J. 1993;7:155-60.

4. Wang PL, Bao Y, Yee MC, Barrett SP, Hogan GJ, Olsen MN, et al. Circular RNA is expressed across the eukaryotic tree of life. PLoS One. 2014;9(6):e90859.

5. Sanger HL, Klotz G, Riesner D, Gross HJ, Kleinschmidt AK. Viroids are singlestranded covalently closed circular RNA molecules existing as highly basepaired rod-like structures. Proc Natl Acad Sci U S A. 1976;73:3852-6.

6. Arnberg AC, Van Ommen GJ, Grivell LA, Van Bruggen EF, Borst P. Some yeast mitochondrial RNAs are circular. Cell. 1980;19:313-9.

7. Salzman J, Gawad C, Wang PL, Lacayo N, Brown PO. Circular RNAs are the predominant transcript isoform from hundreds of human genes in diverse cell types. PLoS One. 2012:7:e30733.

8. Jeck WR, Sorrentino JA, Wang K, Slevin MK, Burd CE, Liu J, et al. Circular RNAs are abundant, conserved, and associated with ALU repeats. RNA. 2013; 19:141-57.

9. Chen LL, Yang L. Regulation of circRNA biogenesis. RNA Biol. 2015;12:381-8.

10. Memczak S, Jens M, Elefsinioti A, Torti F, Krueger J, Rybak A, et al. Circular RNAs are a large class of animal RNAs with regulatory potency. Nature. 2013:495:333-8

11. Li P, Chen S, Chen H, Mo X, Li T, Shao Y, et al. Using circular RNA as a novel type of biomarker in the screening of gastric cancer. Clin Chim Acta. 2015; 444:132-6.

12. Panda AC, Abdelmohsen K, Gorospe M. RT-qPCR detection of senescenceassociated circular RNAs. Methods Mol Biol. 2017;1534:79-87.
13. Maiese K. Disease onset and aging in the world of circular RNAs. J Transl Sci. 2016;2(6):327-9.

14. Wang F, Nazarali AJ, Ji S. Circular RNAs as potential biomarkers for cancer diagnosis and therapy. Am J Cancer Res. 2016;6(6):1167-76.

15. Dong Y, He D, Peng Z, Peng W, Shi W, Wang J, et al. Circular RNAs in cancer: an emerging key player. J Hematol Oncol. 2017;10(1):2.

16. Hou LD, Zhang J. Circular RNAs: an emerging type of RNA in cancer. Int J Immunopathol Pharmacol. 2017;30(1):1-6.

17. Hansen TB, Jensen $\mathrm{Tl}$, Clausen BH, Bramsen JB, Finsen B, Damgaard CK, et al. Natural RNA circles function as efficient microRNA sponges. Nature. 2013; 495:384-8.

18. Thomas LF, Saetrom P. Circular RNAs are depleted of polymorphisms at microRNA binding sites. Bioinformatics. 2014;30:2243-6.

19. Peng L, Yuan XQ, Li GC. The emerging landscape of circular RNA ciRS-7 in cancer. Oncol Rep. 2015:33(6):2669-74.

20. Ashwal-Fluss R, Meyer M, Pamudurti NR, Ivanov A, Bartok O, Hanan M, et al. circRNA biogenesis competes with pre-mRNA splicing. Mol Cell. 2014;56(1):55-66

21. Song $X$, Zeng $Z$, Wei $H$, Wang $Z$. Alternative splicing in cancers: from aberrant regulation to new therapeutics. Semin Cell Dev Biol. 2018;75:13-22.

22. Li LJ, Leng RX, Fan YG, Pan HF, Ye DQ. Translation of noncoding RNAs: focus on IncRNAs, pri-miRNAs, and circRNAs. Exp Cell Res. 2017;361(1):1-8.

23. Pamudurti NR, Bartok O, Jens M, Ashwal-Fluss R, Stottmeister C, Ruhe L, et al. Translation of CircRNAs. Mol Cell. 2017:66(1):9-21.e7.

24. Wang Y, Wang Z. Efficient backsplicing produces translatable circular mRNAs. RNA. 2015;21(2):172-9.

25. Abe N, Matsumoto K, Nishihara M, Nakano Y, Shibata A, Maruyama H, et al. Rolling circle translation of circular RNA in living human cells. Sci Rep. 2015; 5:16435.

26. Yang $Y$, Fan $X$, Mao $M$, Song $X, W u P$, Zhang $Y$, et al. Extensive translation of circular RNAs driven by N6-methyladenosine. Cell Res. 2017;27(5):626-41.

27. Yang Y, Gao X, Zhang M, Yan S, Sun C, Xiao F, et al. Novel Role of FBXW7 Circular RNA in Repressing Glioma Tumorigenesis. J Natl Cancer Inst. 2018:110(3):304-15.

28. Panagopoulos K, Cross-Knorr S, Dillard C, Pantazatos D, Del Tatto M, Mills D, et al. Reversal of chemosensitivity and induction of cell malignancy of a non-malignant prostate cancer cell line upon extracellular vesicle exposure. Mol Cancer. 2013;12(1):118.

29. Li X, Wang S, Zhu R, Li H, Han Q, Zhao RC. Lung tumor exosomes induce a pro-inflammatory phenotype in mesenchymal stem cells via NFKB-TLR signaling pathway. J Hematol Oncol. 2016;9:42.

30. Raposo G, Stoorvogel W. Extracellular vesicles: exosomes, microvesicles, and friends. J Cell Biol. 2013;200(4):373-83.

31. Zhang X, Yuan X, Shi H, Wu L, Qian H, Xu W. Exosomes in cancer: small particle, big player. J Hematol Oncol. 2015;8:83.

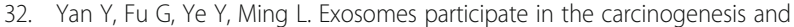
the malignant behavior of gastric cancer. Scand J Gastroenterol. 2017;52(5): 499-504.

33. Bonizzato A, Gaffo E, Te Kronnie G, Bortoluzzi S. CircRNAs in hematopoiesis and hematological malignancies. Blood Cancer J. 2016;6(10):e483.

34. Kim KM, Abdelmohsen K, Mustapic M, Kapogiannis D, Gorospe M. RNA in extracellular vesicles. Wiley Interdiscip Rev RNA. 2017;8(4):e1413.

35. Lasda E, Parker R. Circular RNAs co-precipitate with extracellular vesicles: a possible mechanism for circRNA clearance. PLoS One. 2016;11(2):e0148407.

36. Choi $\mathrm{H}$, Lee DS. Illuminating the physiology of extracellular vesicles. Stem Cell Res Ther. 2016;7(1):55.

37. Qu S, Song W, Yang X, Wang J, Zhang R, Zhang Z, et al. Microarray expression profile of circular RNAs in human pancreatic ductal adenocarcinoma. Genom Data. 2015:5:385-7.

38. Hao L, Hao X, Wang H, Liu Z, He Y, Pu M, et al. Circular RNA expression profile of pancreatic ductal adenocarcinoma revealed by microarray. Cell Physiol Biochem. 2016;40(6):1334-44.

39. Xuan L, Qu L, Zhou H, Wang P, Yu H, Wu T, et al. Circular RNA: a novel biomarker for progressive laryngeal cancer. Am J Transl Res. 2016;8(2):932-9.

40. Su H, Lin F, Deng X, Shen L, Fang Y, Fei Z, et al. Profiling and bioinformatics analyses reveal differential circular RNA expression in radioresistant esophageal cancer cells. J Transl Med. 2016;14(1):225

41. Zhu M, Xu Y, Chen Y, Yan F. Circular BANP, an upregulated circular RNA that modulates cell proliferation in colorectal cancer. Biomed Pharmacother. 2017:88:138-44

42. Song X, Zhang N, Han P, Moon BS, Lai RK, Wang K, et al. Circular RNA profile in gliomas revealed by identification tool UROBORUS. Nucleic Acids Res. 2016;44(9):e87. 
43. Nair AA, Niu N, Tang X, Thompson KJ, Wang L, Kocher JP, et al. Circular RNAs and their associations with breast cancer subtypes. Oncotarget. 2016; 7(49):80967-79.

44. Dou Y, Cha DJ, Franklin JL, Higginbotham JN, Jeppesen DK, Weaver AM, et al. Circular RNAs are down-regulated in KRAS mutant colon cancer cells and can be transferred to exosomes. Sci Rep. 2016:6:37982.

45. Sand M, Bechara FG, Sand D, Gambichler T, Hahn SA, Bromba M, et al. Circular RNA expression in basal cell carcinoma. Epigenomics. 2016;8(5):619-32.

46. Sand M, Bechara FG, Gambichler T, Sand D, Bromba M, Hahn SA, et al. Circular RNA expression in cutaneous squamous cell carcinoma. J Dermatol Sci. 2016;83(3):210-8.

47. Sui W, Shi Z, Xue W, Ou M, Zhu Y, Chen J, et al. Circular RNA and gene expression profiles in gastric cancer based on microarray chip technology. Oncol Rep. 2017;37(3):1804-14.

48. Pan $\mathrm{H}$, Li T, Jiang Y, Pan C, Ding Y, Huang Z, et al. Overexpression of circular RNA ciRS-7 abrogates the tumor suppressive effect of miR-7 on gastric cancer via PTEN/PI3K/AKT signaling pathway. J Cell Biochem. 2018;119(1):440-6.

49. Yin WB, Yan MG, Fang X, Guo JJ, Xiong W, Zhang RP. Circulating circular RNA hsa_circ_0001785 acts as a diagnostic biomarker for breast cancer detection. Clin Chim Acta. 2017; https://doi.org/10.1016/j.cca.2017.10.011.

50. Yang W, Du WW, Li X, Yee AJ, Yang BB. Foxo3 activity promoted by noncoding effects of circular RNA and Foxo3 pseudogene in the inhibition of tumor growth and angiogenesis. Oncogene. 2016;35(30):3919-31.

51. Du WW, Fang L, Yang W, Wu N, Awan FM, Yang Z, et al. Induction of tumor apoptosis through a circular RNA enhancing Foxo3 activity. Cell Death Differ. 2017;24(2):357-70.

52. Zhang $H$, Wang G, Ding C, Liu P, Wang R, Ding W, et al. Increased circular RNA UBAP2 acts as a sponge of miR-143 to promote osteosarcoma progression. Oncotarget. 2017;8(37):61687-97.

53. Fang $Y$, Xue JL, Shen $\mathrm{Q}$, Chen J, Tian L. MicroRNA-7 inhibits tumor growth and metastasis by targeting the phosphoinositide 3-kinase/Akt pathway in hepatocellular carcinoma. Hepatology. 2012;55(6):1852-62.

54. Herrero-Sánchez MC, Rodríguez-Serrano C, Almeida J, San Segundo L, Inogés S, Santos-Briz Á, et al. Targeting of PI3K/AKT/mTOR pathway to inhibit T cell activation and prevent graft-versus-host disease development. J Hematol Oncol. 2016:9(1):113.

55. Yu L, Gong X, Sun L, Zhou Q, Lu B, Zhu L. The circular RNA Cdr1as act as an oncogene in hepatocellular carcinoma through targeting miR-7 expression. PLoS One. 2016;11(7):e0158347.

56. Xue J, Liu Y, Luo F, Lu X, Xu H, Liu X, et al. Circ100284, via miR-217 regulation of $\mathrm{EZH} 2$, is involved in the arsenite-accelerated cell cycle of human keratinocytes in carcinogenesis. Biochim Biophys Acta. 2017;1863(3): 753-63.

57. Yang X, Xiong Q, Wu Y, Li S, Ge F. Quantitative proteomics reveals the regulatory networks of circular RNA CDR1as in hepatocellular carcinoma cells. J Proteome Res. 2017;16(10):3891-902.

58. Wan L, Zhang L, Fan K, Cheng ZX, Sun QC, Wang JJ. Circular RNA-ITCH suppresses lung cancer proliferation via inhibiting the Wnt/beta-catenin pathway. Biomed Res Int. 2016;2016:1579490.

59. Li F, Zhang L, Li W, Deng J, Zheng J, An M, et al. Circular RNA ITCH has inhibitory effect on ESCC by suppressing the Wnt/beta-catenin pathway. Oncotarget. 2015;6(8):6001-13.

60. Zhong Z, LV M, Chen J. Screening differential circular RNA expression profiles reveals the regulatory role of circTCF25-miR-103a-3p/miR-107-CDK6 pathway in bladder carcinoma. Sci Rep. 2016:6:30919.

61. Chen Y, Sun Y, Rao Q, Xu H, Li L, Chang C. Androgen receptor (AR) suppresses miRNA-145 to promote renal cell carcinoma (RCC) progression independent of VHL status. Oncotarget. 2015;6(31):31203-15.

62. Wang $K$, Sun $Y$, Tao W, Fei $X$, Chang C. Androgen receptor (AR) promotes clear cell renal cell carcinoma (cCRCC) migration and invasion via altering the circHIAT1/miR-195-5p/29a-3p/29c-3p/CDC42 signals. Cancer Lett. 2017 394:1-12

63. Jiang $Y$, Yim SH, Xu HD, Jung SH, Yang SY, Hu HJ, et al. A potential oncogenic role of the commonly observed E2F5 overexpression in hepatocellular carcinoma. World J Gastroenterol. 2011;17(4):470-7.

64. Xie $H$, Ren $X$, Xin $S$, Lan $X, L u ~ G$, Lin $Y$, et al. Emerging roles of circRNA 001569 targeting miR-145 in the proliferation and invasion of colorectal cancer. Oncotarget. 2016;7(18):26680-91.

65. Li Y, Zheng F, Xiao X, Xie F, Tao D, Huang C, et al. CircHIPK3 sponges miR558 to suppress heparanase expression in bladder cancer cells. EMBO Rep. 2017;18(9):1646-59.
66. Sun $M$, Song $H$, Wang S, Zhang C, Zheng L, Chen F, et al. Integrated analysis identifies microRNA-195 as a suppressor of Hippo-YAP pathway in colorectal cancer. J Hematol Oncol. 2017;10(1):79.

67. Wang $X$, Zhang $Y$, Huang L, Zhang J, Pan F, Li B, et al. Decreased expression of hsa_circ_001988 in colorectal cancer and its clinical significances. Int J Clin Exp Pathol. 2015:8(12):16020-5.

68. Zhang R, Xu J, Zhao J, Wang X. Silencing of hsa_circ_0007534 suppresses proliferation and induces apoptosis in colorectal cancer cells. Eur Rev Med Pharmacol Sci. 2018;22(1):118-26.

69. Wang F, Wang J, Cao X, Xu L, Chen L. Hsa_circ_0014717 is downregulated in colorectal cancer and inhibits tumor growth by promoting p16 expression. Biomed Pharmacother. 2018;98:775-82.

70. Weng W, Wei Q, Toden S, Yoshida K, Nagasaka T, Fujiwara T, et al. Circular RNA ciRS-7 - A promising prognostic biomarker and a potential therapeutic target in colorectal cancer. Clin Cancer Res. 2017:23(14):3918-28.

71. Jayachandran A, Dhungel B, Steel JC. Epithelial-to-mesenchymal plasticity of cancer stem cells: therapeutic targets in hepatocellular carcinoma. J Hematol Oncol. 2016;9(1):74

72. Khemlina G, Ikeda S, Kurzrock R. The biology of hepatocellular carcinoma: implications for genomic and immune therapies. Mol Cancer. 2017;16(1):149.

73. Fu L, Wu S, Yao T, Chen Q, Xie Y, Ying S, et al. Decreased expression of hsa circ_0003570 in hepatocellular carcinoma and its clinical significance. J Clin Lab Anal. 2018;32(2):e22239.

74. Han D, Li J, Wang H, Su X, Hou J, Gu Y, et al. Circular RNA circMTO1 acts as the sponge of microRNA-9 to suppress hepatocellular carcinoma progression. Hepatology. 2017;66(4):1151-64.

75. Shang X, Li G, Liu H, Li T, Liu J, Zhao Q, et al. Comprehensive circular RNA profiling reveals that hsa_circ_0005075, a new circular RNA biomarker, is involved in hepatocellular carcinom development. Medicine (Baltimore). 2016:95(22):e3811.

76. Yao Z, Luo J, Hu K, Lin J, Huang H, Wang Q, et al. ZKSCAN1 gene and its related circular RNA (circZKSCAN1) both inhibit hepatocellular carcinoma cell growth, migration and invasion but through different signaling pathways. Mol Oncol. 2017;11(4):422-37.

77. Xia J, Wang H, Li S, Wu Q, Sun L, Huang H, et al. lon channels or aquaporins as novel molecular targets in gastric cancer. Mol Cancer. 2017;16(1):54.

78. Lu R, Shao Y, Ye G, Xiao B, Guo J. Low expression of hsa_circ_0006633 in human gastric cancer and its clinical significances. Tumour Biol. 2017;39(6): 1010428317704175

79. Shao Y, Li J, Lu R, Li T, Yang Y, Xiao B, Guo J. Global circular RNA expression profile of human gastric cancer and its clinical significance. Cancer Med. 2017;6(6):1173-80

80. Li J, Zhen L, Zhang Y, Zhao L, Liu H, Cai D, et al. Circ-104916 is downregulated in gastric cancer and suppresses migration and invasion of gastric cancer cells. Onco Targets Ther. 2017;10:3521-9.

81. Chen S, Li T, Zhao Q, Xiao B, Guo J. Using circular RNA hsa_circ_0000190 as a new biomarker in the diagnosis of gastric cancer. Clin Chim Acta. 2017; 466:167-71

82. Zhao Q, Chen S, Li T, Xiao B, Zhang X. Clinical values of circular RNA 0000181 in the screening of gastric cancer. J Clin Lab Anal. 2018;32(4):e22333.

83. Xu ZQ, Yang MG, Liu HJ, Su CQ. Circular RNA hsa_circ_0003221 (circPTK2) promotes the proliferation and migration of bladder cancer cells. J Cell Biochem. 2018:119(4):3317-25.

84. Xia W, Qiu M, Chen R, Wang S, Leng X, Wang J, et al. Circular RNA has_circ_ 0067934 is upregulated in esophageal squamous cell carcinoma and promoted proliferation. Sci Rep. 2016;6:35576.

85. Huang G, Zhu H, Shi Y, Wu W, Cai H, Chen X. Cir-ITCH plays an inhibitory role in colorectal cancer by regulating the Wnt/beta-catenin pathway. PLoS One. 2015;10(6):e0131225.

86. Kong Z, Wan X, Zhang $Y$, Zhang $P$, Zhang $Y$, Zhang $X$, et al. Androgenresponsive circular RNA circSMARCA5 is up-regulated and promotes cell proliferation in prostate cancer. Biochem Biophys Res Commun. 2017; 493(3):1217-23

87. Zheng J, Liu X, Xue Y, Gong W, Ma J, Xi Z, et al. TTBK2 circular RNA promotes glioma malignancy by regulating miR-217/HNF1 beta/Derlin-1 pathway. J Hematol Oncol. 2017;10(1):52.

88. Yang P, Qiu Z, Jiang Y, Dong L, Yang W, Gu C, et al. Silencing of CZNF292 circular RNA suppresses human glioma tube formation via the Wnt/betacatenin signaling pathway. Oncotarget. 2016;7(39):63449-55.

89. Suzuki S, Yokobori T, Altan B, Hara K, Ozawa D, Tanaka N, et al. High stathmin 1 expression is associated with poor prognosis and 
chemoradiation resistance in esophageal squamous cell carcinoma. Int J Oncol. 2017; https://doi.org/10.3892/ijo.2017.3899.

90. Jimenez-Jimenez E, Mateos P, Aymar N, Roncero R, Ortiz I, Gimenez M, et al. Radiotherapy volume delineation using 18F-FDG-PET/CT modifies gross node volume in patients with oesophageal cancer. Clin Transl Oncol. 2018; https://doi.org/10.1007/s12094-018-1879-3.

91. Phi LTH, Sari IN, Yang YG, Lee SH, Jun N, Kim KS, et al. Cancer stem cells (CSCs) in drug resistance and their therapeutic implications in cancer treatment. Stem Cells Int. 2018;2018:5416923.

92. Gao D, Zhang X, Liu B, Meng D, Fang K, Guo Z, Li L. Screening circular RNA related to chemotherapeutic resistance in breast cancer. Epigenomics. 2017; 9(9):1175-88.

93. Xiong W, Jiang $Y X, A i$ YQ, Liu S, Wu XR, Cui JG, et al. Microarray analysis of long non-coding RNA expression profile associated with 5-fluorouracilbased chemoradiation resistance in colorectal cancer cells. Asian Pac J Cancer Prev. 2015;16(8):3395-402.

94. Liu Y, Dong Y, Zhao L, Su L, Luo J. Circular RNA-MTO1 suppresses breast cancer cell viability and reverses monastrol resistance through regulating the TRAF4/Eg5 axis. Int J Oncol. 2018. https://doi.org/10.3892/ijo.2018.4485,

95. Kun-Peng Z, Xiao-Long M, Chun-Lin Z. Overexpressed circPVT1, a potential new circular RNA biomarker, contributes to doxorubicin and cisplatin resistance of osteosarcoma cells by regulating ABCB1. Int J Biol Sci. 2018; 14(3):321-30.

96. Yang C, Yuan W, Yang X, Li P, Wang J, Han J, et al. Circular RNA circ-ITCH inhibits bladder cancer progression by sponging miR-17/miR-224 and regulating p21, PTEN expression. Mol Cancer. 2018;17(1):19.

97. Sang M, Meng L, Sang Y, Liu S, Ding P, Ju Y, et al. Circular RNA ciRS-7 accelerates ESCC progression through acting as a miR-876-5p sponge to enhance MAGE-A family expression. Cancer Lett. 2018;14(3):321-30.

98. Guo JN, Li J, Zhu CL, Feng WT, Shao JX, Wan L, et al. Comprehensive profile of differentially expressed circular RNAs reveals that hsa_circ_0000069 is upregulated and promotes cell proliferation, migration, and invasion in colorectal cancer. Onco Targets Ther. 2016;9:7451-8.

99. Zhuo F, Lin H, Chen Z, Huang Z, Hu J. The expression profile and clinical significance of circRNA0003906 in colorectal cancer. Onco Targets Ther. 2017:10:5187-93.

100. Ji W, Qiu C, Wang M, Mao N, Wu S, Dai Y. Hsa_circ_0001649: A circular RNA and potential novel biomarker for colorectal cancer. Biochem Biophys Res Commun. 2018:497(1):122-6.

101. Wang J, Li X, Lu L, He L, Hu H, Xu Z. Circular RNA hsa_circ_0000567 can be used as a promising diagnostic biomarker for human colorectal cancer. J Clin Lab Anal. 2018;32(5):e22379.

102. Zeng K, Chen X, Xu M, Liu X, Hu X, Xu T, et al. CircHIPK3 promotes colorectal cancer growth and metastasis by sponging miR-7. Cell Death Dis. 2018;9(4):417.

103. Xu L, Zhang M, Zheng X, Yi P, Lan C, Xu M. The circular RNA ciRS-7 (Cdrlas) acts as a risk factor of hepatic microvascular invasion in hepatocellular carcinoma. J Cancer Res Clin Oncol. 2017;143(1):17-27.

104. Qin M, Liu G, Huo X, Tao X, Sun X, Ge Z, et al. Hsa_circ_0001649: a circular RNA and potential novel biomarker for hepatocellular carcinoma. Cancer Biomark. 2016;16(1):161-9.

105. Jiang W, Wen D, Gong L, Wang Y, Liu Z, Yin F. Circular RNA hsa_circ_0000673 promotes hepatocellular carcinoma malignance by decreasing miR-767-3p targeting SET. Biochem Biophys Res Commun. 2018;500(2):211-6.

106. Zhong L, Wang Y, Cheng Y, Wang W, Lu B, Zhu L, et al. Circular RNA circC3P1 suppresses hepatocellular carcinoma growth and metastasis through miR-4641/PCK1 pathway. Biochem Biophys Res Commun. 2018; 499(4):1044-9.

107. Zhang Y, Liu H, Li W, Yu J, Li J, Shen Z, et al. CircRNA_100269 is downregulated in gastric cancer and suppresses tumor cell growth by targeting miR-630. Aging (Albany NY). 2017;9(6):1585-94.

108. Huang M, He YR, Liang LC, Huang Q, Zhu ZQ. Circular RNA hsa_circ_ 0000745 may serve as a diagnostic marker for gastric cancer. World J Gastroenterol. 2017;23(34):6330-8.

109. Xie Y, Shao Y, Sun W, Ye G, Zhang X, Xiao B, et al. Downregulated expression of hsa_circ_0074362 in gastric cancer and its potential diagnostic values. Biomark Med. 2018;12(1):11-20.

110. Chen J, Li Y, Zheng Q, Bao C, He J, Chen B, et al. Circular RNA profile identifies circPVT1 as a proliferative factor and prognostic marker in gastric cancer. Cancer Lett. 2017;1(388):208-19.
111. Shao Y, Chen L, Lu R, Zhang X, Xiao B, Ye G, et al. Decreased expression of hsa_circ_0001895 in human gastric cancer and its clinical significances. Tumour Biol. 2017;39(4):1010428317699125.

112. Tian M, Chen R, Li T, Xiao B. Reduced expression of circRNA hsa_circ 0003159 in gastric cancer and its clinical significance. J Clin Lab Anal. 2018; 32(3):e22281.

113. Sun H, Tang W, Rong D, Jin H, Fu K, Zhang W, et al. Hsa_circ_0000520, a potential new circular RNA biomarker, is involved in gastric carcinoma. Cancer Biomark. 2018;21(2):299-306.

114. Wang N, Gu Y, Li L, Wang F, Lv P, Xiong Y, et al. Circular RNA circMYO9B facilitates breast cancer cell proliferation and invasiveness via upregulating FOXP4 expression by sponging miR-4316. Arch Biochem Biophys. 2018;653:63-70.

115. He R, Liu P, Xie X, Zhou Y, Liao Q, Xiong W, et al. circGFRA1 and GFRA1 act as ceRNAs in triple negative breast cancer by regulating miR-34a. J Exp Clin Cancer Res. 2017;36(1):145.

116. Yao JT, Zhao SH, Liu QP, Lv MQ, Zhou DX, Liao ZJ, et al. Over-expression of CircRNA_100876 in non-small cell lung cancer and its prognostic value. Pathol Res Pract. 2017;213(5):453-6.

117. Zhao F, Han Y, Liu Z, Zhao Z, Li Z, Jia K. circFADS2 regulates lung cancer cells proliferation and invasion via acting as a sponge of miR-498. Biosci Rep. 2018; https://doi.org/10.1042/BSR20180570.

118. Zong L, Sun Q, Zhang H, Chen Z, Deng Y, Li D, et al. Increased expression of circRNA 102231 in lung cancer and its clinical significance. Biomed Pharmacother. 2018;102:639-44.
Ready to submit your research? Choose BMC and benefit from:
- fast, convenient online submission
- thorough peer review by experienced researchers in your field
- rapid publication on acceptance
- support for research data, including large and complex data types
- gold Open Access which fosters wider collaboration and increased citations
- maximum visibility for your research: over $100 \mathrm{M}$ website views per year
At BMC, research is always in progress.
Learn more biomedcentral.com/submissions 